\title{
Conversion of Mountain Beech Coppices into High Forest: An Example for Ecological Intensification
}

\author{
Walter Mattioli ${ }^{1} \cdot$ Barbara Ferrari $^{1} \cdot$ Diego Giuliarelli $^{1} \cdot$ Leone Davide Mancini $^{1}$ \\ Luigi Portoghesi ${ }^{1} \cdot$ Piermaria Corona $^{2}$
}

Received: 29 September 2014/ Accepted: 8 June 2015/Published online: 13 June 2015

(C) Springer Science+Business Media New York 2015

\begin{abstract}
Converting beech coppices into high forest stands has been promoted in the last decades as a management goal to attenuate the negative effects that frequent clearcutting may have on soil, landscape, and biodiversity conservation. The silvicultural tool usually adopted is the gradual thinning of shoots during the long span of time required to complete the conversion, that also allows the owner to keep harvesting some wood. This research reports and discusses, in the light of the ecological intensification approach, the results achieved from an experimental test started more than 25 years ago in a 42 -year-old beech (Fagus sylvatica L.) coppice with standards in central Italy. The effects of various thinning intensities (three treatments plus a control) on the stand growth and structure are assessed by successive forest inventories. Analyses are
\end{abstract}

Walter Mattioli

walter.mattioli@unitus.it

Barbara Ferrari

barbara.ferrari@unitus.it

Diego Giuliarelli

dgiuliarelli@unitus.it

Leone Davide Mancini

leone.mancini@unitus.it

Luigi Portoghesi

lporto@unitus.it

Piermaria Corona

piermaria.corona@entecra.it

1 Department for Innovation in Biological, Agro-food and Forest systems (DIBAF), University of Tuscia, via S. Camillo de Lellis, 01100 Viterbo, Italy

2 Consiglio per la ricerca in agricoltura e l'analisi dell'economia agraria, Forestry Research Centre (CRA-SEL), viale S. Margherita 80, 52100 Arezzo, Italy integrated by spatial indices to assess stem density and canopy cover. Converting beech coppices into high forest through gradual thinning of shoots proves to be an effective step down the road to silvicultural systems characterized by continuous forest cover, as a tool of ecological intensification suitable to guarantee both public and private interests. Thinning has led to stands with fewer but larger stems, thus accelerating the long conversion process while maintaining both wood harvesting capability and environmental services.

Keywords Thinning - Continuous cover - Coppice with standards $\cdot$ Fagus sylvatica $\cdot$ Italy

\section{Introduction}

The concept of ecological intensification has been developed as an alternative approach for mainstream agriculture and forestry to meet societal challenges (Egger 1986; FAO 2009). In recent studies, ecological intensification has been focused on the use of biological regulation to manage ecosystems, at field, farm, and landscape scales (Matson et al. 1997; Doré et al. 2011; Médiène et al. 2011). According to Chevassus au Louis and Griffon (2008), ecological intensification concerns the intensification in the use of the natural functionalities that ecosystems offer. It can be formally defined as a knowledge-intensive process that requires optimal management of nature's ecological functions and biodiversity to improve ecological system performance and efficiency (FAO 2011): it means designing more productive, sustainable production systems that save on inputs and are less harmful to the environment. The challenge of ecological intensification is to reduce reliance 